\title{
Emergy approach for the environmental sustainability assessment of the urban water system of Genoa (NW Italy)
}

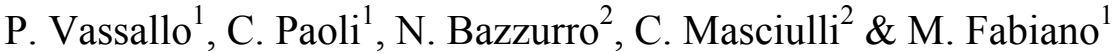 \\ ${ }^{I}$ Department for the Study of Territory and its Resources, \\ University of Genoa, Genoa, Italy \\ ${ }^{2}$ Fondazione AMGA, Genoa, Italy
}

\begin{abstract}
Water has been defined as the oil of the twenty-first century; this is the reason why improving water managing techniques and making them sustainable is the way through which economic growth should be attained. The purpose of this study is to provide a valid scientific instrument to administrations in order to hit this mark. The emergy concept was used to evaluate the sustainability of the water cycle managed by the AMGA group in an area (the province of Genoa, Italy), consisting of $1513 \mathrm{Km}^{2}$ and 52 municipalities (also comprehending the city of Genoa). Emergy is defined as the available energy of one kind previously used up directly or indirectly to create a product or an energy flow. Analysis has concerned the study of process phases and the calculation of a number of emergetic indices. Some of the emergetic indices calculated for the Genoese system were compared with those obtained by a similar study previously performed on another process of water management (Bologna, Italy). The emergy evaluation shows a good efficiency of the system, a great ability at exploiting natural resources and a low dependence from external sources. Further improvements in the level of sustainability of the process could be foreseen by the reduction of the leaks of water during management, by the improvement of the pipeline design and by the employment of more durable materials and if possible characterized by lower values of transformity.
\end{abstract}

Keywords: water cycle, emergy, environmental sustainability, thermodynamic approach, water management. 


\section{Introduction}

Water is a fundamental resource, integral to all environmental functions and human purpose. It belongs to the group of renewable resources that are extinguishable [1] and there are threats to, and pressure on it, all over the world. Developed countries water use is strictly related to a strong management of the resource that has to be carefully planned to avoid possible damages to important environmental features, or permanent loss of the quality level of the resource.

A number of different studies focused on the problems related to the planning of water use and recently some approaches to the integrated (e.g. [2-5]) or sustainable management have been performed (e.g. [6-8]). However there is a lack of attention to a practical and adaptable tool for the implementation and evaluation of integrated and sustainable management. There is the need of new indicators able to assess for an ecologically sustainable water management program, in which human needs for water are met by storing and diverting water in a manner that can sustain or restore the ecological integrity of affected river ecosystems [9].

According to the sustainability concept, aiming to reach a better level of sustainability in exploiting the water resource, it is important to evaluate both the quality of the internal resources of the catchment basin and the contribution of the external ones that are involved in the system to maintain its level of activity and its equilibrium. On the other hand it is important to consider the exportations out of the system in terms of refusals and energy degradation. Traditional analyses, usually employed in studying sustainability of systems with great interconnection of both human and natural aspects, generally consider only one of two different aspects: the economic and the environmental one. A methodology that considers both systems (ecological and economic) and that allows defining the importance of products as to a limited amount of resources available is necessary for a sustainable development. Natural and human inputs contribute to the economic growth of the systems, but economics analyses are not able to monetize natural resources.

Emergy analysis is a possible answer to this problem, being a method of analysis able to consider both natural and human system and to compare their products. Emergy accounting methodology has developed over the last three decades [10-12] as a tool for environmental policy and to evaluate quality of resources in the dynamics of complex systems. Emergy could be defined as the sum of all inputs of energy directly or indirectly required by a process to provide a given product when the inputs are expressed in the same form (or type) of energy, usually solar energy. Choice of solar energy derived from the consideration that it is the most important energy involved in all biogeochemical processes of the heart. Emergy analysis takes into account the quality of each form of energy multiplying each quantity of energy by its solar transformity. Solar transformity is defined as solar emergy per unit energy (sej/j) $[13,14]$. The amount of input emergy (expressed as solar emergy) per unit output energy is termed, solar transformity. Transformity can be considered both a quality indicator, according to Lotka-Odum's maximum power principle $[15,16]$ and an 
efficiency indicator because a lower transformity needed to obtain a product means a lower (and better) exploitation of resources during the process. We could refer to emergy as a sustainability indicator cause it allows evaluating the quantity and quality (in terms of renewability) of resources employed in a process. Moreover by the comparison of inputs and outputs to a process in emergy terms it is possible to assess the efficiency of the entire process or of specific compartments of the productive chain.

This paper deals with the application of the emergy analysis for the assessment of the level of sustainability of the urban water management of the city of Genoa (NW Italy), controlled by AMGA group. AMGA Group works on the Italian and international markets offering a series of services requiring highly specialized know-how such as technological support, technical and organizational assistance, and skill building and knowledge sharing programs. Experience consolidated in over 60 years in the business and a rapid process of ongoing technological innovation make the AMGA Group a landmark and a highly qualified reference for utility operators and public authorities looking for a quality response to the problems of environmental protection and network management.

\section{Materials and methods}

\subsection{Study area}

The study we are going to present deals on the environmental sustainability analysis of the water cycle managed by AMGA in Genoa (NW Italy), and in 51 neighboring municipalities, for a total of 761000 inhabitants living in 1513 $\mathrm{Km}^{2}$ (Figure 1).

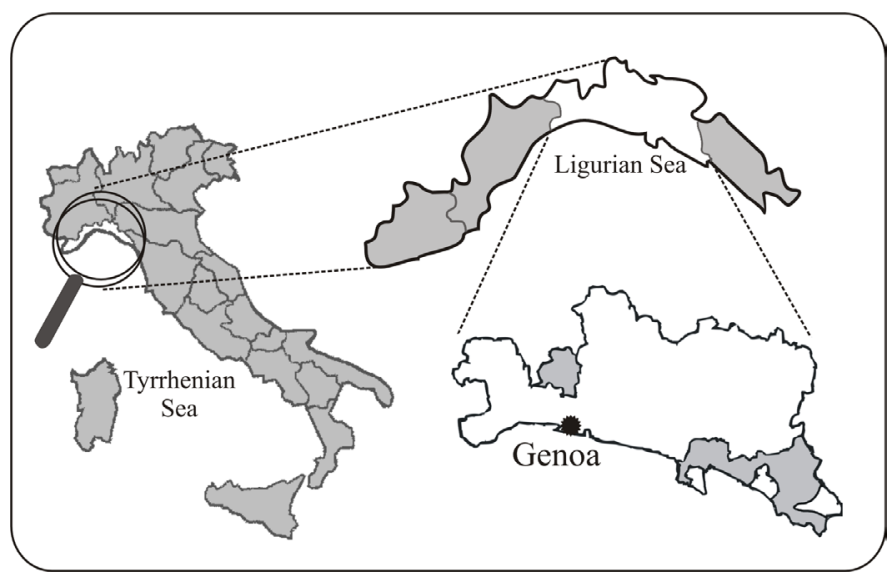

Figure 1: $\quad$ Location of the study area. In white analysed municipalities.

The analysed service manages roughly $6 \cdot 10^{7} \mathrm{~m}^{3}$ water a year and consists of seven subsequent steps: collection, adduction, purification for drinking, 
distribution, waste water collection and waste water treatment. The greatest part of collected water is stored in two artificial lakes but a minor extent is pumped from a number of wells or from the main river crossing the city of Genoa (Bisagno River). Collected water is addressed to purification that is performed almost completely in two plants working with sand filters. Just before the purification process the kinetic energy assumed by water is spent for electricity production in turbines. Water distribution in the province of Genoa historically represented a difficult problem to be solved due to the geographical features of the region with a rapid gradient between hills and sea, and to the scattered distribution of the involved municipalities. Finally waste water treatment is performed in eight plants displayed all along the Genoese coast.

\subsection{Emergy analysis}

Emergy is the work that the biosphere has to do, in order to maintain a system far from equilibrium [17]. The higher the emergy flux necessary to sustain a system or a process, the higher is their hierarchical level and the usefulness that can be expected from them (Maximum Empower Principle [13]).

Emergy analysis is used to evaluate all the energetic fluxes needed to reach a certain product or to obtain a service and to measure the environmental stress due to the human activities. It considers a system with larger boundaries, including all the inputs that contributed to form a product, including environmental inputs that are regarded as free in energy analysis [18]. The first step in the emergy analysis has been the achievement of a systemic diagram drawn using an appropriate symbology developed by Odum. Natural inputs are represented on the left side of the systemic diagram while moving clockwise along the diagram, resources are ordered following a decreasing rate of renewability. All the fluxes and objects in the diagram have been converted in emergy terms by the application of appropriate transformities or conversion factors. Detailed description of the calculation procedures and related equations are available for the readers on request to the authors.

In this research we considered as the total renewable contribution the sum of two different inputs: geothermal heat and chemical potential of rain. Some other natural contributions (i.e. solar radiation, wind, geopotential of water) were calculated and then not added to the total emergy value cause all these source inputs to the system result from parallel processing of the global emergy driving the biosphere. This procedure, widely employed in this kind of studies, avoids counting the same phenomenon twice under different names and has been drawn by Odum [16].

The total emergy value it is a numeral value that needs some comparisons to be discussed, nevertheless it could be better understood calculating some indices for the assessment of the sustainability level of the process. These indices arise from the different nature of the inputs involved in the emergy calculation. The percentages of renewable local sources $(\mathrm{R})$, local non-renewable sources $(\mathrm{N})$ and external (non-renewable) sources (F) combined in a number of ways bring to different results. 
Afterwards to reach a better insight in the analyzed water cycle each one of the seven phases of the process has been separately considered. This approach was already followed in a previous similar study applied in six municipalities on the western side of the province of Bologna [19] managed by the SEABO company. However, cause it is not possible to leave out of consideration the sequential nature of the process, the link between phases it has been maintained by means of transformities. In fact the transformity applied to the water, as input to a phase, is the one obtained as output at the end of the previous one. By the analysis of the different phases it is possible to obtain both indices of sustainability and transformities of water at the end of each process and consequently detect those that more affect the level of sustainability and the total emergy of the entire water cycle.

\section{Results}

The diagram in Figure 2 has been suitably developed aiming to represent the fluxes involved in the process considered in this study. In the diagram it is shown the entire process regarding the water cycle managed by AMGA.

The algebraic sum of all the represented fluxes counting both renewable and non-renewable resources brings to the total emergy required to maintain the water cycle. In this case total emergy resulted equal to $3.89 \mathrm{E}+20 \mathrm{sej} / \mathrm{year}$. Indices calculated for the examined process (and related equations) are reported in Table 1.

Table 1: $\quad$ Emergetic indices for the water cycle managed by AMGA (Genoa).

\begin{tabular}{|l|c|c|}
\hline Index & Formula & Value \\
\hline $\boldsymbol{O}_{\mathbf{R}}($ renewable percentage $)$ & $\mathrm{R} / \mathrm{U}$ & $64.56 \%$ \\
\hline Emergy / ind & $\mathrm{U} /\left(\mathrm{n}^{\circ}\right.$ ind. $)$ & $5.10 \mathrm{E}+14$ \\
\hline EYR & $\mathrm{U} / \mathrm{F}$ & 4.08 \\
\hline ELR (= EIR) & $\mathrm{F}+\mathrm{N} / \mathrm{R}(=\mathrm{F} / \mathrm{R}+\mathrm{N})$ & 0.38 \\
\hline SI & $\mathrm{EYR} / \mathrm{ELR}$ & 10.8 \\
\hline
\end{tabular}

Results can be better understood and depicted through the analysis of the different phases composing the water cycle and detected results are represented through the fulfilment of some pie charts. Emergetic percentage contributions of water and anthropic activities are represented in Figure 3A. In Figure 3B are represented only contributions related with human operations on natural resources.

\section{Discussions}

Indices reported in Table 1 identify a good level of environmental sustainability of the water cycle managed by AMGA. In fact, the sustainability index resulted significantly higher than 1 letting us infer that the examined process have a net contribution to society [20]. 


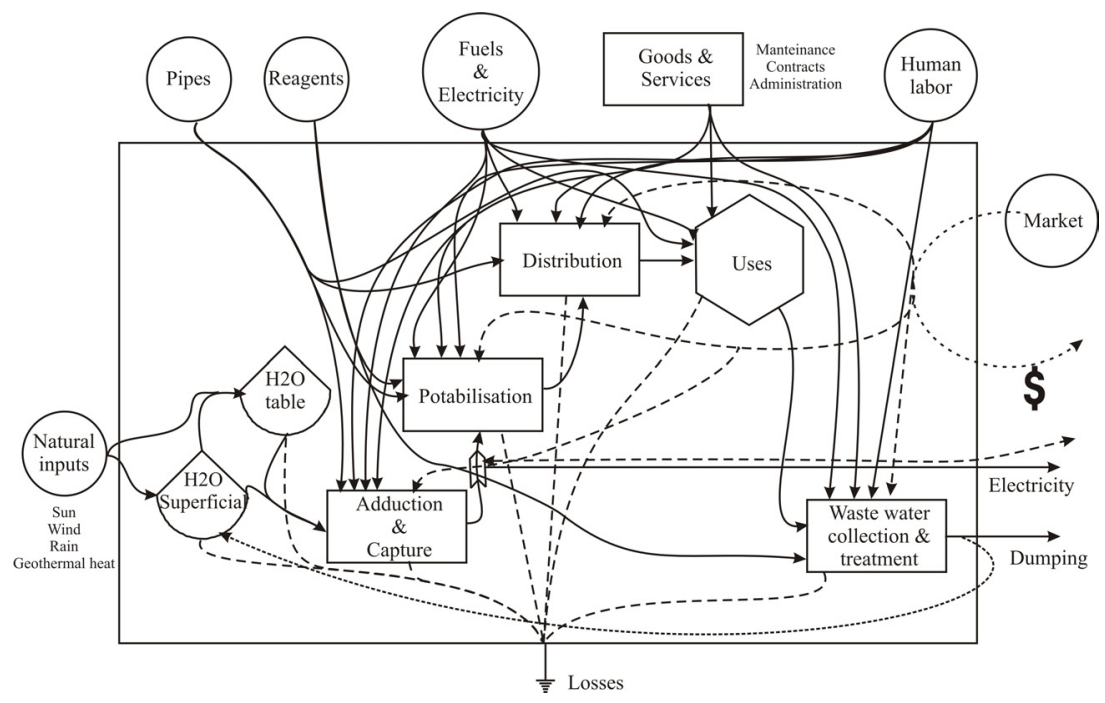

Figure 2: $\quad$ System diagram of AMGA productive cycle with Odum's symbols.

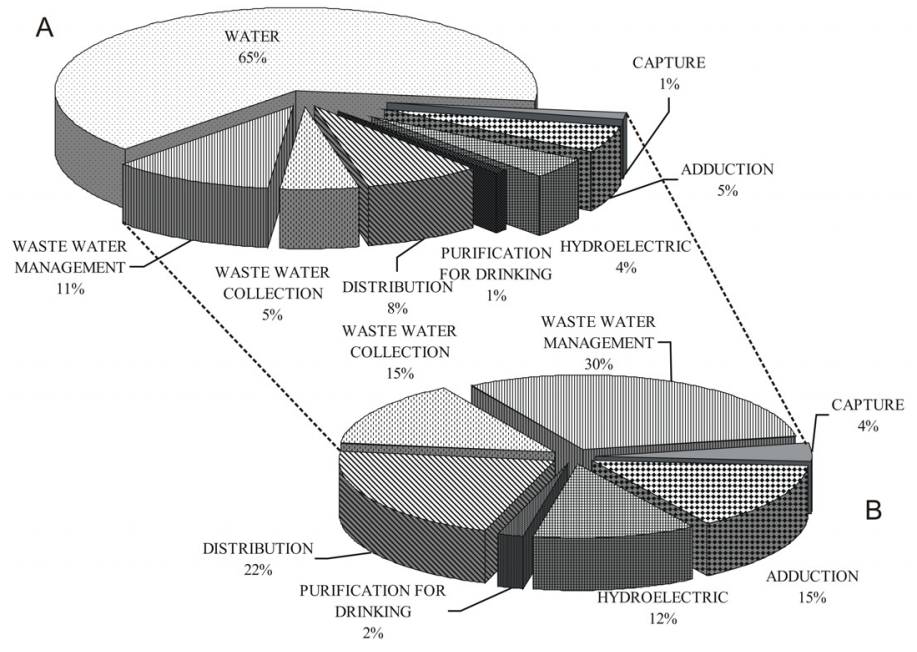

Figure 3: Emergy percentages of all the contributions in the entire water cycle (A) and in the artificial water cycle (B).

As a direct consequence both ELR and EYR display good values showing an intense exploitation of free, natural, renewable resources instead of a relative low employment of technological inputs (also confirmed by a high $\emptyset_{R}$ value). Moreover these results receive confirmation if compared with the SEABO management of the water cycle (Figure 4). On the contrary transformity and emergy per person diverges from what previously assumed cause the AMGA process displays a strongly higher emergy request for each inhabitant and for 
each gram of water. The reason could be inferred if the different contributions to total emergy in the two considered processes are compared. In Genoa, in fact, a great quantity of emergy (both renewable and not) is needed to perform the process (Table 2).

Table 2: Different emergetic contributions and comparison with a similar system.

\begin{tabular}{|l|c|c|}
\hline & AMGA Genoa & SEABO Bologna \\
\hline Renewable resources emergy & $2.50 \mathrm{E}+20$ & $2.77 \mathrm{E}+17$ \\
\hline Non renewable resources emergy & $9.59 \mathrm{E}+19$ & $7.88 \mathrm{E}+18$ \\
\hline Total emergy & $3.89 \mathrm{E}+20$ & $8.16 \mathrm{E}+18$ \\
\hline
\end{tabular}

Nevertheless AMGA process, even if strongly expensive (in emergy terms), displayed a higher level of sustainability cause it is mostly based on the exploitation of renewable resources $(\sim 65 \%)$ while SEABO is to all practical completely dependent on non renewable resources $(\sim 97 \%)$.

If the different phases of the artificial water cycle are separately considered it results clear that waste water management needs the highest emergy to be performed (Figure 3). This is in fact the process that more than the others needs anthropic intervention such as reactants, electricity and labour. What is more interesting is the huge contribution of the distribution process strongly affected by emergy contribution due to pipelines covering material (sand, concrete, etc.).

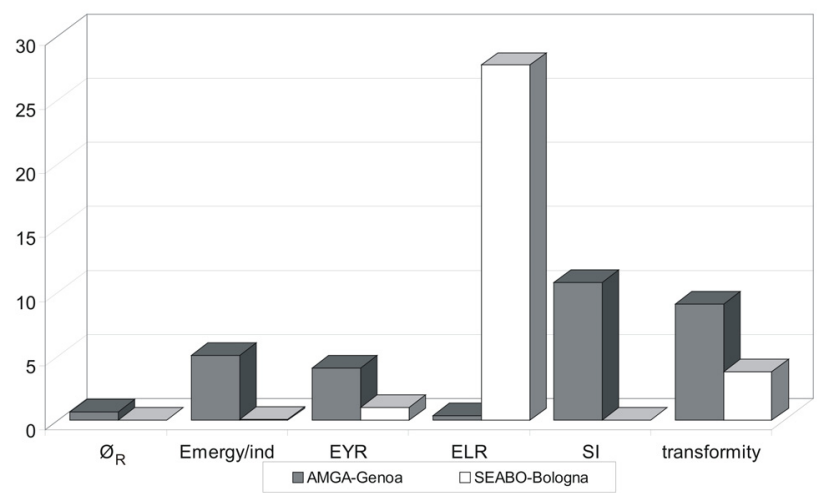

Figure 4: Emergetic indices comparison between AMGA and SEABO systems.

This result could be linked to the relative old age of pipes that need higher quantity of covering material to support the water pressure. As a consequence of the great quantity of emergy needed for these two phases water transformity suffers huge increases when distributed or treated during the cycle (Figure 5A).

On the other hand considering purification for drinking phase it results that it affects lightly the emergetic cost of the entire process (Figure 3 ) but produces a strong increase of transformity (Figure 5A; percentage of total transformity 
increase $=11 \%$ ). This rise it is not due to a real emergy cost spent in performing this phase but it is ascribable to considerable water losses. The emergy needed till this moment it is thus split up to a lesser extent of water bringing to a noticeable increase in transformity.

The final step of the analysis consists in the calculation of the monetary value that can be ascribed to the effort made, in terms of emergy, to carry out the process. This emergetic cost is calculated as ratio of the total emergy of the process to the transformity of current money. Emergetic cost for water at the end of the water cycle is $4.11 € / \mathrm{m}^{3}$, while the price that users bear to profit by water is more than four times lower. This comparison shows that economics undervalue the resource and in Figure 5B it is shown the differences between the economic and emergetic costs for each phase. It is clearly showed that for some phases economy fits well the emergy effort needed for performing (capture, waste water collection) but others (purification for drinking, distribution) are unbalanced with significantly higher emergy costs in respect of the economic ones. Finally it has to be noticed that the natural resource water, considered as free by the economy, displays the highest difference in respect of the cost valued in emergetic terms.

\section{Conclusions}

AMGA's urban water management system displayed a good level of sustainability with low environmental loading and great ability in exploiting natural resources. Emergetic indices assessed AMGA water cycle as more sustainable in respect of a similar production in a different Italian province.

A

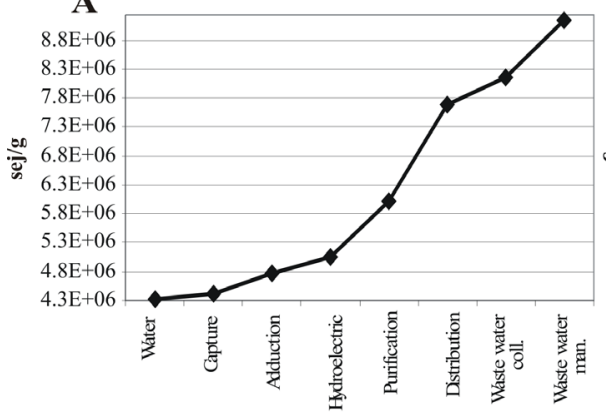

B

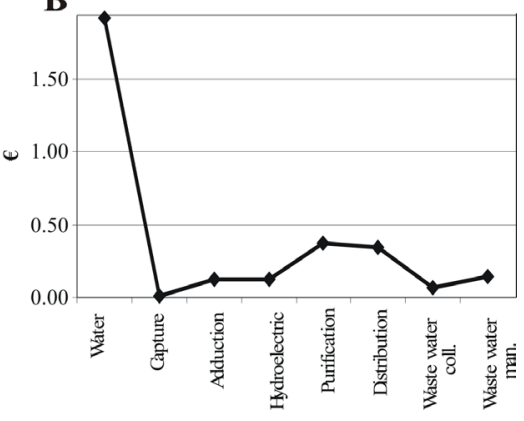

Figure 5: Transformity increases during the artificial water cycle.

Nonetheless by the comparison with Seabo water cycle management it results clear that the AMGA one needs more emergy to be performed showing higher transformity and value for each gram of water. This latter result appeared to be related to a significant unbalance in the emergetic value of the natural resource that in Genoa seems to be more expensive and rare.

During the artificial water cycle phases mainly affecting emergy were waste water treatment, affected by a great expense of external resources, and water distribution, marked by an excess of pipeline cover material. These evaluations 
are supported by the analysis of transformities trend that shows a great increase during waste water treatment and distribution but also during purification for drinking. This latter information can be explained considering water loss characterising this phase that causes a noticeably increase of the ratio between the emergy requested and the quantity of water carried to the distribution.

A further analysis brought to the comparison between the economic price and the emergetic one and displayed the underestimation by economics of the real value both of natural resources and anthropic activities.

Finally, by the application of this analysis, authors judge that emergy could be employed as a powerful tool for the management cause it is easily applicable to other similar systems, allows to assess the actual level of sustainability (through the comparison with similar productive systems), identifies changes in sustainability level (if applied at different times). The presented approach could thus be proposed as a valid instrument devoted to help local officials and internal decision makers detecting the better ways of development.

\section{References}

[1] Sustainable Resource Unit (A2), Toward a European strategy for the sustainable use of natural resources. European commission, DG environment, 9 pp, 2002.

[2] Mitchell, B., Integrated water management. Integrated Water Management: International Experiences and Perspectives, ed. B. Mitchell, Bellhaven Press: London, England, pp. 1-21, 1990.

[3] Viessman, W., Integrated water management. Water Resources Update, 106, pp. 2-12, 1996.

[4] Grigg, N.S., Integrated water resources management: who should lead, who should pay? Journal of the American Water Resources Association, 35(3), pp. 527-534, 1999.

[5] Braga, B.P.F., Integrated urban water resources management: a challenge into the 21 st century. Water Resources Development, 17(4), pp. 581-599, 2001.

[6] Mitchell, B., Shrubsole, D.A., Reorienting to achieve sustainability in Canadian water management. Canadian Water Resources Journal, 19(4), pp. 335-348, 1994.

[7] Letcher, R.A., Giupponi C., Policies and tools for sustainable water management in the European Union, Environmental Modelling \& Software, 20(2), pp. 93-98, 2005.

[8] Zacharias, I., Koussouris, T., Sustainable Water Management in the European Islands, Physical chemical Earth, 25(3), pp. 233-236, 2000.

[9] Richter, B.D., Mathews, R., Harrison, D.L., Wigingtond, R., Ecologically sustainable water management: managing river flows for ecological integrity. Ecological Applications, 13(1), pp. 206-224, 2002.

[10] Odum, H.T., Systems ecology, Wiley, New York, 1983 
[11] Odum H.T., Embodied energy, foreign trade, and welfare of nations, Integrations of economy and ecology, ed. Jansson, University of Stockholm Sweden, pp. 185-200, 1984.

[12] Odum H.T., Ecological economics, Encyclopedia of the Environment, ed. Eblen, R.A., Eblen W.R., New York, pp. 159-161, 1994.

[13] Odum, H.T., Self-organization, transformity, and information, Science, 242, pp. 1132-1139, 1988a.

[14] Odum, H.T., Emergy, Environmental and Public Policy: a guide to the analysis of system. Regional Seas Reports and Studies, 95, United Nations Environment Programme, pp. 109, 1988b.

[15] Odum H.T., Pinkerton R.C., Time speed regulator: the optimum efficiency for maximum power output in physical and biological systems, American scientist, 43, pp. 331-343, 1955.

[16] Odum, H.T., Environmental Accounting. Emergy and environmental decision making, J. Wiley \& sons, New York, 1996.

[17] Bastianoni, S., Marchettini, N., Emergy/Exergy as a measure of the level of organization of systems, Ecological Modelling, 99, pp. 33-40, 1997.

[18] Bastianoni, S., Nielsen, S.N, Marchettini, N., Jørgensen, S.E., Use of thermodynamic functions for expressing some relevant aspects of sustainability, International Journal of Energy Research, 29 (1), pp. 5364, 2005.

[19] Bastianoni, S., Fugaro, L., Principi, I., Tiezzi, E., Implementazione di un sistema di contabilità ambientale su scala provinciale e intercomunale, Provincia di Bologna, 2001.

[20] Ulgiati, S., Brown, M.T., Monitoring patterns of sustainability in natural and man-made ecosystems, Ecological Modelling, 108, pp. 23-36, 1998. 